\title{
Libros
}

\section{El capitán Guillermo Dupaix y su álbum arqueológico de 1794}

FICHA BIBLIOGRÁFICA

Leonardo López Luján

El capitán

Guillermo Dupaix

y su álbum arqueológico de 1794

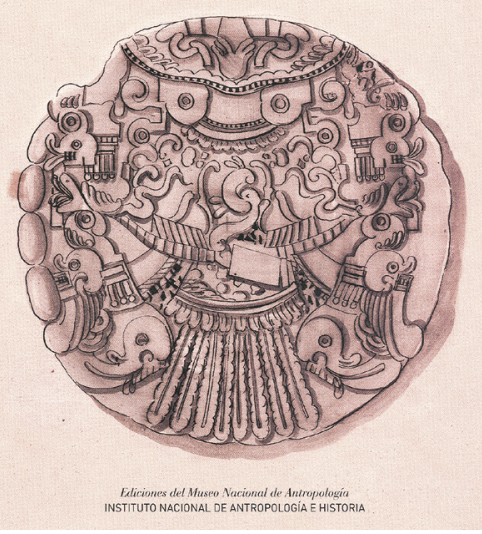

Leonardo López Luján, El capitán Guillermo Dupaix y su álbum arqueológico de 1794, México: Museo Nacional de Antropología, Instituto Nacional de Antropología e Historia, 2015, 304 págs. ISBN. 978-607-484-656-0

\section{Jorge Maier Allende Real Academia de Bellas Artes de San Fernando}

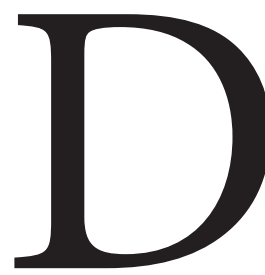

esde hace algunos lustros el Prof. Dr. Leonardo López Luján trabaja con ahínco en la fascinante historia de la arqueología mexicana y sus orígenes. El capitán retirado del Regimiento de Dragones de México, Guillermo Dupaix (1746-1818), ha sido con frecuencia objeto de su interés (López Luján, 2011; López Luján y Pérez, 2013), ya que fue el director y principal responsable de la Real Expedición Anticuaria de México, que llevó a cabo entre 1805 y 1808, y a la que ha dedicado también especial atención (Fauvet-Berthelot, López Luján y Guimarâes 2007; Fauvet-Berthelot, López Luján y Guimarâes, 2012). Con esta nueva contribución el Prof. López Luján nos ha dado a conocer la notable colección de dibujos de antigüedades mexicanas que el anticuario militar realizó en el curso de sus "correrías particulares" o viajes exploratorios y de estudio previos a la expedición oficial, así como otros manuscritos, que se conservan hoy en día en la Biblioteca Nacional de Antropología e Historia 
de México. Precisamente estas “correrías” y sus contrastados conocimientos en antigüedades, fueron las que le cualificaron a Dupaix para que Carlos IV le encargara la dirección de la Real Expedición Anticuaria de México, por Real Orden de 2 de mayo de 1804. Esta expedición científica, fue sin duda una de las iniciativas más relevantes de la Arqueología, dentro y fuera de México, en los albores del siglo XIX.

La Real Expedición Anticuaria de México, representa el punto culminante que la Arqueología alcanzó en la política cultural de la Corona Española, como bien señala el Prof. López Luján en su estudio introductorio y hemos puesto de relieve en varias ocasiones (Almagro-Gorbea y Maier, 2010; 2012). Este proceso tuvo su origen a comienzos de la centuria ilustrada durante el reinado de Felipe V, especialmente a partir de su matrimonio con Elisabetta Farnese, más conocida en el mundo hispánico como Isabel de Farnesio. Pero especialmente con la empresa que el hijo de éstos, Carlos de Borbón, llevó a cabo en el reino de las Dos Sicilias, -fruto de esta política cultural- con el descubrimiento, excavación, conservación y publicación de las ruinas de las antiguas ciudades de Herculano primero y Pompeya después y de sus antigüedades, que causaron un impacto sin precedentes en el mundo cultural europeo y americano y transformaron las ciencias de la antigüedad. En efecto, desde entonces fue en aumento paulatino el interés por la historia antigua y las antigüedades en Nueva España, de los que se cuenta con un buen número de ejemplos ilustrativos en los que ahora no cabe detenerse. Hay que señalar que este interés también fue auspiciado desde España por la Real Academia de la Historia, en su calidad de Cronista de Indias, y que desde la corporación se intentó estimular a las autoridades civiles, militares y eclesiásticas del Nuevo Mundo a que se preocuparan por recoger y estudiar las antigüedades, tal y como también se hacía en el solar peninsular y en Italia.

Uno de los elementos claves de la Arqueología Ilustrada fue la instauración de las expediciones científicas, normalmente promovidas por la Corona en el caso de la Monarquía Hispánica, con el objeto de examinar, analizar y registrar directamente los monumentos y antigüedades, por lo que frecuentemente estaban dotadas por una "instrucción" y con un dibujante cualificado. La primera expedición arqueológica de esta naturaleza -y en muchos sentidos modelo de las posteriores- fue la que la Real Academia de la Historia le encargó en 1752 a Luis José Velázquez, marqués de Valdeflores, conocida como el Viaje de las Antigüedades de España (Velázquez, 2015), promovida por Fernando VI y su todopoderoso Ministro el marqués de la Ensenada. También se llevaron a cabo en el reino de las Dos Sicilias promovido por Carlos de Borbón poco antes de la de España, en el que destaca el Viaje arqueológico de Sicilia del P. Giuseppe María Pancrazi, publicado en 1752. A estas siguieron otras iniciativas en España de menor envergadura como el Viaje de Talavera la Vieja, la antigua Augustobriga, de Ignacio Hermosilla o el Viaje del Obispado de Osma de Juan Bautista Lópezrraez (Maier, 2012). A finales de la centuria contamos con nuevas iniciativas entre las que cabe destacar el Viaje arquitectónicoanticuario de España de José Ortiz y Sanz, encargado por Carlos III en 1788, pero que no pudo sin embargo llevarlo a cabo hasta casi diez años después, y los viajes de José Cornide, el Viaje a Segobriga (1793) y, especialmente, el Viaje de Extremadura y Portugal (1798-1801), en el que le acompañaron el mexicano, natural de Oaxaca, Manuel Carrillo de Albornoz, oficial $2^{\circ}$ de la Secretaría del Consejo y Cámara de Indias en el Departamento de Perú, el arquitecto gallego, Melchor de Prado y Mariño, al que se deben todos los 
dibujos que de este viaje se conservan, y Narciso Heredia (futuro Conde de Ofalia), catedrático de Filosofía y Matemáticas de Granada.

Este fue sin duda el modelo que se trasladó al Nuevo Mundo y que en el caso novohispano tuvo su primer fruto en la expedición a las ruinas de Palenque promovida por Carlos III y que culmina en el reinado de Carlos IV con la Real Expedición Anticuaria de México dirigida por el Capitán Dupaix, acompañado por el dibujante Luciano Castañeda, académico de la de Real Academia de Bellas de Artes de San Carlos de México.

Guillermo Dupaix se une así a esta pléyade de expedicionarios arqueológicos que hicieron de la Arqueología una ciencia histórica universal aplicable a cualquier contexto cultural.

El material gráfico reunido por el Capitán Dupaix en su expedición arqueológica oficial y sus textos descriptivos, sufrió varios avatares que son bien conocidos y han sido descritos, e incluso publicados, en varias ocasiones (Alcina, 1995, 149-158; Palop y Cerdá, 1997, 129-152). No lo eran por el contrario el conjunto de dibujos y manuscritos de sus "correrías particulares", que es lo que precisamente nos da a conocer en este magnífico catálogo de exposición el Prof. López Luján. Todo este fondo documental se conserva en la Biblioteca Nacional del Antropología e Historia de México y está formado por cuatro conjuntos. Tres de ellos se componen de dibujos a lápiz, parte de los cuales son utilizados para la ilustrar el estudio introductorio del catálogo. El cuarto grupo se compone de 22 dibujos a tinta y aguada que formaban un cuadernillo manuscrito titulado Descripción de Monumentos antiguos Mexicanos. Este conjunto de dibujos es el que se presenta sistemáticamente en el catálogo, acompañado por dos textos manuscritos más.

El catálogo de la exposición está estructurado en cuatro apartados. El primero lo constituye el estudio introductorio, "El Capitán Dupaix y sus "correrías particulares", en el que tras centrar al personaje en el contexto histórico del México de finales del siglo XVIII y los descubrimientos arqueológicos, de su llegada a México y de sus aficiones anticuarias, se trata sobre los avatares de la documentación de la Real Expedición Anticuaria, para a continuación centrarse en la documentación sobre sus viajes exploratorios privados, en la que se presta especial atención a la serie de dibujos expuestos.

El segundo apartado está dedicado al análisis pormenorizado de los dibujos que se presentan en fichas individualizadas acompañadas por la ficha de los objetos arqueológicos representados. El tercer apartado está dedicado al manuscrito De la Piedra Triunfal, esto es, de la conocida Piedra de Tizoc, adicionado con los textos que sobre este objeto cultual escribieron Antonio León y Gama y Alexander von Humboldt. Y, finalmente, el cuarto y último apartado está dedicado a la transcripción del manuscrito, donado en 2014 al Instituto Nacional de Antropología e Historia, por los herederos del conocido arqueólogo mexicano Ignacio Bernal, titulado Investigación $1^{a}$ en 1794 de México, Cuernavaca, Tetlama y Xochicalco, con el que se completa este importante conjunto documental.

En definitiva, este catálogo analítico del material gráfico más importante de las "correrías particulares" del capitán Guillermo Dupaix constituye una importante contribución al conocimiento del origen de la arqueología mexicana en el tránsito del siglo XVIII al XIX. En efecto, Dupaix es un ejemplo ilustrativo de estos personajes -como fue también el caso de Alcubierre por ejemplo- que ejemplifican y son fruto a su vez del impulso que experimentó la Arqueología como disciplina científica, de su importancia en la política cultural de la monar- 
quía hispánica, y de cómo ensanchó de forma espectacular con su potencialidad el horizonte histórico de los pueblos.

\section{Referencias Bibliográficas:}

Alcina Franch, José, Arqueólogos o Anticuarios. Historia antigua de la Arqueología en la América española, Barcelona, 1995.

Almagro-Gorbea, Martín y Maier Allende, Jorge (Coords.), Corona y Arqueología en el Siglo de las Luces, Madrid, 2010.

Almagro-Gorbea, Martín y Maier Allende, Jorge (eds.), De Pompeya al Nuevo Mundo: la Corona Española y la Arqueología en el siglo XVIII, Madrid, 2012.

Fauvet-Berthelot, Marie-France, López Luján, Leonardo y Guimarâes, Susana, "Six personnages en quête d'objets: histoire de la collection archéologique de la Real Expedición Anticuaria en Nouvelle Espagne", Gradhiva, Revue d'anthropologie et de muséologie, París, Musée duquai Branly, n. 6, 2007, p. 104-126.

Fauvet-Berthelot, Marie-France, López Luján, Leonardo y Guimarâes, Susana, “The Real Expedicion Anticuaria collection" en Fanning the Sacred Flame: Mesoamerican Studies in Honor of H. B. Nicholson, Boulder, UPC, 2012, 461-485.

López Luján, Leonardo "El capitán Guillermo Dupaix y su álbum arqueológico de 1794", Arqueología Mexicana, núm. 109, 2011, pp. 71-81.

López Luján, Leonardo y Pérez, Sonia Arlette, "Las correrías particulares del capitán Guillermo Dupaix, Arqueología Mexicana 19, 2013, 78-89.

Maier Allende, Jorge, "Academicismo y Buen gusto en el origen de la arqueología hispanorromana", Cuadernos de Prehistoria y Arqueología de la Universidad Autónoma de Madrid, 37-38, 2011-12, 75-103.

Palop, Josefina y Cerdá, Alejandro, "Nuevos documentos sobre las expediciones arqueológicas de Guillermo Dupaix por México, 1805-1808”, Revista Española de Antropología Americana 27, 1997, $129-152$.

Velázquez, Luis José, marqués de Valdeflores, Viaje de las Antigüedades de España (1752-1765), edición y estudio Jorge Maier Allende; catálogo de dibujos y mapas Carmen Manso Porto, Madrid, 2015. 